\title{
APPLICATION OF BINAURAL HEARING SYSTEM FOR ASSESSMENT OF ENVIRONMENTAL NOISE IMPACT*
}

\author{
A. Jostaitė and A. Kanapickas \\ Vytautas Magnus University, Vileikos 8, LT-44404 Kaunas, Lithuania \\ E-mail: a.kanapickas@gmf.vdu.lt
}

Received 9 October 2008; revised 21 February 2009; accepted 19 March 2009

\begin{abstract}
In the present work an experimental system is presented that allows one to investigate physical principles of binaural hearing and identification of sound sources. It is checked that at low frequencies interaural time difference (whereas at high frequencies the interaural level difference) cue is preferable for recognizing location of sound sources. At intermediate frequencies human auditory system uses both processes for binaural hearing. Also the effect of traffic noise on binaural hearing is investigated. It is shown that environmental noises consist mainly of low frequency spectral components. Therefore noise is considered to have influence on binaural cues which human auditory system uses for spatial sound localization at low frequencies, i.e. the interaural time difference.
\end{abstract}

Keywords: auditory localization, binaural hearing, environmental noise

PACS: 43.66.Pn, 43.50.Rq, 43.66.Qp

\section{Introduction}

Sound localization is the process by which humans perceive the apparent spatial position of an acoustical source. Human hearing is provided with the ability to evaluate a variety of cues which enables this perception in ways yet not entirely understood. The concept of the process, from the moment when the sound arrives at the ears to the perceived sensation is called binaural hearing [1].

Some environmental conditions interfere with binaural hearing sensation and cause situations when human has decreased possibilities to estimate position of sound sources. For example, because of traffic noise one can indentify an approaching car belatedly. There are many situations when problem of quality of binaural hearing arises: regions near airfields or railways, in some cases wind turbine noise could disturb binaural hearing [2], and looking to the near future, when hydrogen driven cars will appear on roads, the identification of such a soundless moving vehicle will be quite difficult task.

It is obvious that there is a minimal distance, when identification of important sound source is possible. This distance depends on background noise level, on

\footnotetext{
* Results presented at the international conference Radiation Interaction with Material and Its Use in Technologies 2008, 24-27 September 2008, Kaunas, Lithuania
}

informative sound source loudness, and also on different audition reception of individuals [3]. Properties of binaural hearing are not clearly understood, however, in some areas of the acoustic engineering, like stereo sound reproduction, propagation of sound in rooms (theatre, opera, or classroom) practical solutions that meet user requirements have been achieved.

One important property of binaural hearing is to sense the level difference between the ears. This is known as the interaural level difference (ILD) and is a complex quantity depending on head and ear shadowing effects, frequency, and angle of incidence. The difference in time of arrival of sound at the two ears from a sound source displaced from the median plane informs the auditory system about the position of the source. This time delay is referred to as interaural time difference, ITD, and constitutes a very important binaural cue for localization ability.

In general, the localization cues can be divided into two categories: binaural and monaural (spectral) cues. The binaural cues manifest themselves as differences between the ear input signals, whereas evaluation of the spectral cues depends on the ability of a listener to distinguish between the spectrum of the source signal and the effect of the source position on the spectrum. This makes the binaural cues more robust and generally more important for localization [4]. 
There are many situations when the threshold of binaural hearing and, consequentially, the ability of spatial localization are affected by other sounds. If a person is listening to a sound masked by other sounds (particularly, noise), then the threshold for detecting that sound will be elevated as compared to that measured in the absence of the interfering sounds [5]. Long exposure to sound has several different effects on auditory function and on perception. Such exposure to sound can elevate the thresholds of hearing permanently or temporarily, also exposure can influence the subjective loudness and perception of the sound [6]. Loudness adaptation can also change quality of spatial hearing when the subjective loudness of a sound decreases as the exposure to the sound increases.

The behavioural methods for obtaining thresholds of hearing, the methods of calibrating the sound pressure level, and the hearing thresholds have been standardized [7], binaural listening being as a measure of the audibility [6]. However, the impact of environmental noise to the spatial localization of sound sources is not considered as a factor that can have adverse outcome.

In this work experimental system is presented which allows to measure binaural effects purely from physical point of view. Using this system some results about the form of the signals that reach ears are described. Also brief theoretical evaluation of important values is given. Some examples of spectral distributions of environmental noise are presented showing that background noise is usually the sound of low frequencies. Results of measurements have shown that binaural identification of source that emits sound of low frequencies is more difficult and threshold levels of localization of sound source in noisy environment should be higher compared to the situation without interfering sounds.

\section{Experimental set-up}

One of the simplest models of the head is a sphere where the ears are located on each side with a distance $d=2 r$ between the ears. The length of the wave propagation path between a source and an ear depends on the source location and is, in general, different for the two ears. If one assumes that head is transparent, the physical set-up would correspond to two microphones in free-field. Under the assumption that the source distance is relatively large compared to the distance between the microphones, i.e., $q \gg d$, the distances between the source and microphones are approximately $q_{1} \approx q+\Delta q$ and $q_{1} \approx q-\Delta q$, for the left and right microphone, respectively. By simple geometric consider-



Fig. 1. Propagation of sound waves to the microphones mounted on the dummy head.

ations, $\Delta q \approx r \sin \Theta$, as seen in Fig. 1. The difference in arrival times for this simple scenario is given by

$$
\Delta t=\frac{q_{1}-q_{2}}{c}=\frac{2 r \sin \Theta}{c},
$$

where $c$ is the sound wave propagation speed in the air.

However, head is not perfectly spherical and the ears are located slightly towards the back. It is difficult to take into account these facts. In the limit of very low frequencies, the pressures at the ears created by a plane wave source in the presence of a spherical head are the same as those at two points in free space on the interaural axis that are centred on the head and separated by 1.5 times the head diameter [4], i. e.

$$
\Delta t=\frac{3 r \sin \Theta}{c} \text {. }
$$

Additional effect to be included is shadowing by the head. For a source located towards one of the sides, the propagation path is a straight line to the closest ear. For the microphone on the opposite side, the wave needs to propagate around the head. In the limit of very high frequencies, the pressures at the ears created by a plane wave source can be computed by taking the diffraction induced by the head into account. Following a model 


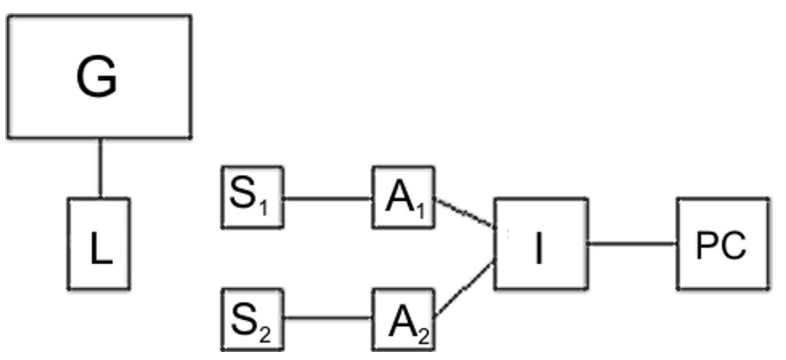

Fig. 2. Experimental set-up for measuring the binaural hearing: $G$ is a low frequency generator, $L$ loudspeaker, $S_{1}$ and $S_{2}$ are microphones, $A_{1}$ and $A_{2}$ are preamplifiers, $I$ interface, $P C$ a computer.

[4] that takes this into account, the time delay $\Delta t$ can be represented as

$$
\Delta t=\frac{r(\sin \Theta+\Theta)}{c},
$$

which is based on diffraction theory. It provides a rough approximation for high frequency sounds.

Experimental set-up is shown in Fig. 2. Data were taken with long duration sine waves on the isolated dummy head of a manikin. These waves were generated with function generator PeakTech 4070, sound reproduced with loudspeaker. Sound sensors $S_{1}$ and $S_{2}$ are specially designed microphones that fit precisely ear holes in dummy head (not shown). These microphones are tied to the preamplifiers $A_{1}$ and $A_{2}$. The distance between microphones $2 r=0.14 \mathrm{~m}$. Angle between the sound source and a normal to the face of dummy head (azimuth $\Theta$ ) was measured with protractor fixed on head holder with $0.5^{\circ}$ error. The sig- nal from microphones was transferred through left and right preamplifiers $A_{1}$ and $A_{2}$ to the computer interface $I$ and further through RS232 cable to the computer. Registered signal was converted into digital form and represented graphically by appropriate software, which controlled all data collection. Time delay between left and right microphone was calculated using built-in function. Fourier transformation was done using another built-in function. Noise analyzer BruelKjaer-2250 was used for measurements of sound levels and spectral representations of field measured noises.

The accuracy of evaluation of the time delay $\Delta t$ between arrivals of sound wave to the right and left microphones depends on the error of azimuth measurement. In the cases when loudspeaker (i. e. sound source) was located near dummy head, the diameter of active surface of loudspeaker was also an important parameter that increased uncertainty of measurements because of finite solid angle the radiation comes out. The distance between microphones was stated to be $0.14 \mathrm{~m}$, however, changes in ambient temperature and some small mismatch in microphone fixation could also add some additional error. All these errors were taken into account and indicated in graphs.

\section{Results}

An example of the sound record using two microphones representing hearing with the two ears is shown in Fig. 3. Frequency of pure tone for this case is taken

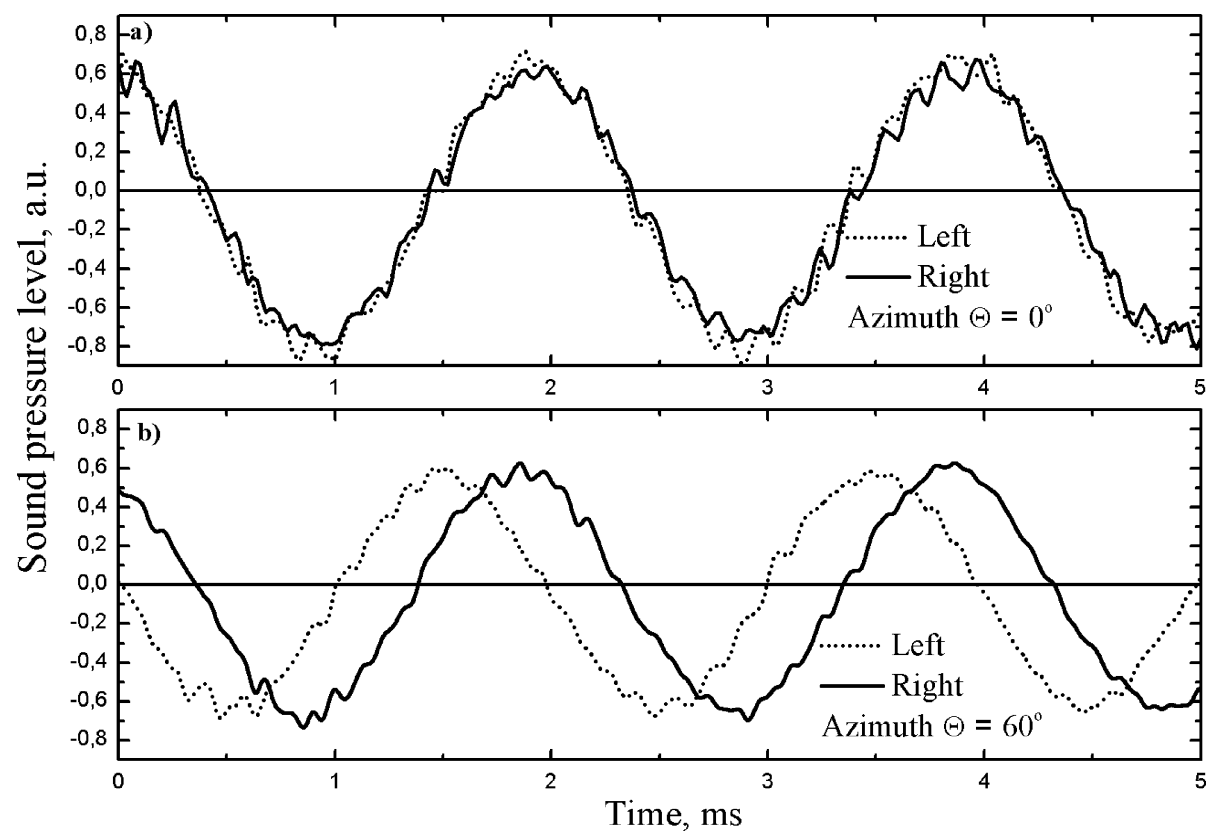

Fig. 3. Signals received by two microphones, representing binaural hearing when azimuth is $0^{\circ}$ and $60^{\circ}$; sound frequency is $500 \mathrm{~Hz}$ in both cases. 




Fig. 4. Dependence of ITD on azimuth $\Theta$ : symbols - $\times-$, -०-, and $-\triangle$ - represent measured ITD for $2 \mathrm{kHz}, 500 \mathrm{~Hz}$, and $360 \mathrm{~Hz}$, respectively. The last one is taken from literature [8]. Lines represent numerical predictions of ITD: calculations were carried out using Eq. (2) for low frequency and Eq. (3) for high frequency tones. $r$ denotes half-distance between microphones.

equal to $500 \mathrm{~Hz}$, azimuth $0^{\circ}$ and $60^{\circ}$. Air temperature during measurements has been $20^{\circ} \mathrm{C}$, velocity of sound in air at this temperature is $c_{\text {air }}=343.4 \mathrm{~m} / \mathrm{s}$. Graphs are not perfect sine curves as one may expect because of room reflections. The exact value of the time delay between received signals is calculated after the fitting of these curves to the sine function. It is obvious that sound signals received by left and right microphones are shifted in time because of different distance to the sound source. When the frequency is equal to $500 \mathrm{~Hz}$, the wavelength of sound is $69 \mathrm{~cm}$. In this case the sound waves are effectively diffracted because their wavelength is longer than the diameter of the head. The ILD is therefore small for frequencies below $500 \mathrm{~Hz}$, so ITD is the main localization cue at distances less than 2-3 metres at low frequencies.

The dependence of the interaural time difference on azimuth $\Theta$ for low-frequency and high-frequency tones is presented in Fig. 4. Theoretical evaluation of ITD is done using Eqs. (2) and (3) for low and high frequencies, respectively. Since the distance between the ears in cited experiment [8] (Kuhn, 1977) has been equal to $18.6 \mathrm{~cm}$, the theoretical curve as well as experimental results for low frequency sound differ. However, in all cases adequacy of experimental measurements to the theoretical predictions can be seen. It should be noted that at the frequency of $2 \mathrm{kHz}$ the phase difference at the two ears is larger than one-half the period of the pure tone wave. Actually, the binaural system rapidly loses sensitivity to any ITD at all as the frequency of the wave increases from 1000 to $1500 \mathrm{~Hz}$. As it will be explained later, in this case the ITD cannot serve as a localization cue. Therefore, one can assume "low frequencies" as being lower than $1000 \mathrm{~Hz}$ and "high frequencies" being higher than $1500 \mathrm{~Hz}$.

Figure 5 shows graphical representation of ITD exhibition at lower (upper graph) and higher frequencies. The wavelength $\lambda$ of pure sound wave at the frequency $\nu=150 \mathrm{~Hz}$ is about $2.3 \mathrm{~m}$, i. e. $\lambda \gg d$, where $d=2 r$ is distance between the ears. At this distance the change of the amplitude of sound wave is small. Contrary to generally accepted view this should make it difficult to use ITD as a localization cue at very low frequencies.

When the delay is exactly half a period, the signals at the two ears are exactly out of phase. Whenever the ITD is equal to or larger than one-half the period of the acoustic event, additional ambiguities occur: the listener will not be able to distinguish whether the source is located on the left side of the head or on the right one.

With the increase of frequency the scattering by the head increases rapidly and at $4000 \mathrm{~Hz}$ the head casts a significant shadow. In this case comparison between intensities in the left and right ears, i. e. ILD, becomes the main cue for sound localization. This property of recorded acoustic signals is seen in Fig. 5 (lower graph): the difference of sound loudness in each microphone (i. e. in each ear) differs significantly.

According to the classic duplex theory of binaural 




Fig. 5. Graphical representation of ITD exhibition at (a) lower and (b) higher frequencies.

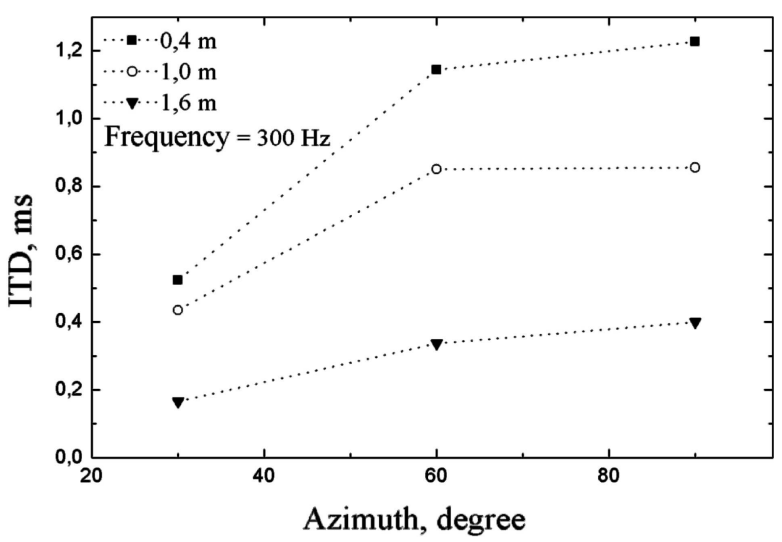

Fig. 6. ITD at different distances of sound source.

localization [3], the ITDs are used for localization at low frequencies and ILDs at high frequencies. However, the theory is not fully correct even if it does reflect the frequency-dependent importance of ITDs and ILDs. For sinusoidal signals the effectiveness of the ITDs does indeed decrease at high frequencies. This happens for two physiological reasons. First of all, above approximately $1000 \mathrm{~Hz}$, the period of a sinusoid is shorter than range of naturally occurring delays, making determination of the actual ITD of the sinusoidal signal ambiguous.

Figure 6 shows that with the increase of the distance the time difference between the arrivals of sound waves decreases. This can be explained by the extremely low distances from sound source to the microphones.

In free-field the changes in the localization cues as a function of distance for sound sources beyond approximately $2-3 \mathrm{~m}$ are perceptually negligible. The perception of intermediate distances $(3-15 \mathrm{~m})$ is mainly based on loudness. At distances greater than that, the frequency-dependent absorption of the air also creates spectral distance cues. However, the utilization of both loudness and spectral cues requires familiarity with or making some assumptions about the source signal. Consequently, both at intermediate and large distances, large discrepancies between the distance of the auditory event and the sound source may occur for unfamiliar or amplified sounds [4].

To study human ability to localize sound, the spectra of some environmental noises were investigated. Figure 7 presents the spectrum of wind turbine noise and traffic noise spectrum. The first one was measured di-

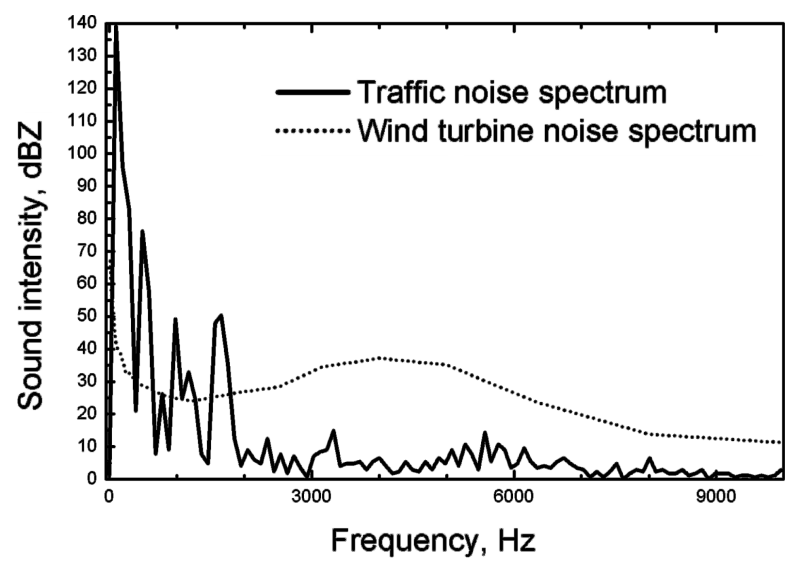

Fig. 7. Examples of spectra of environmental noises. 


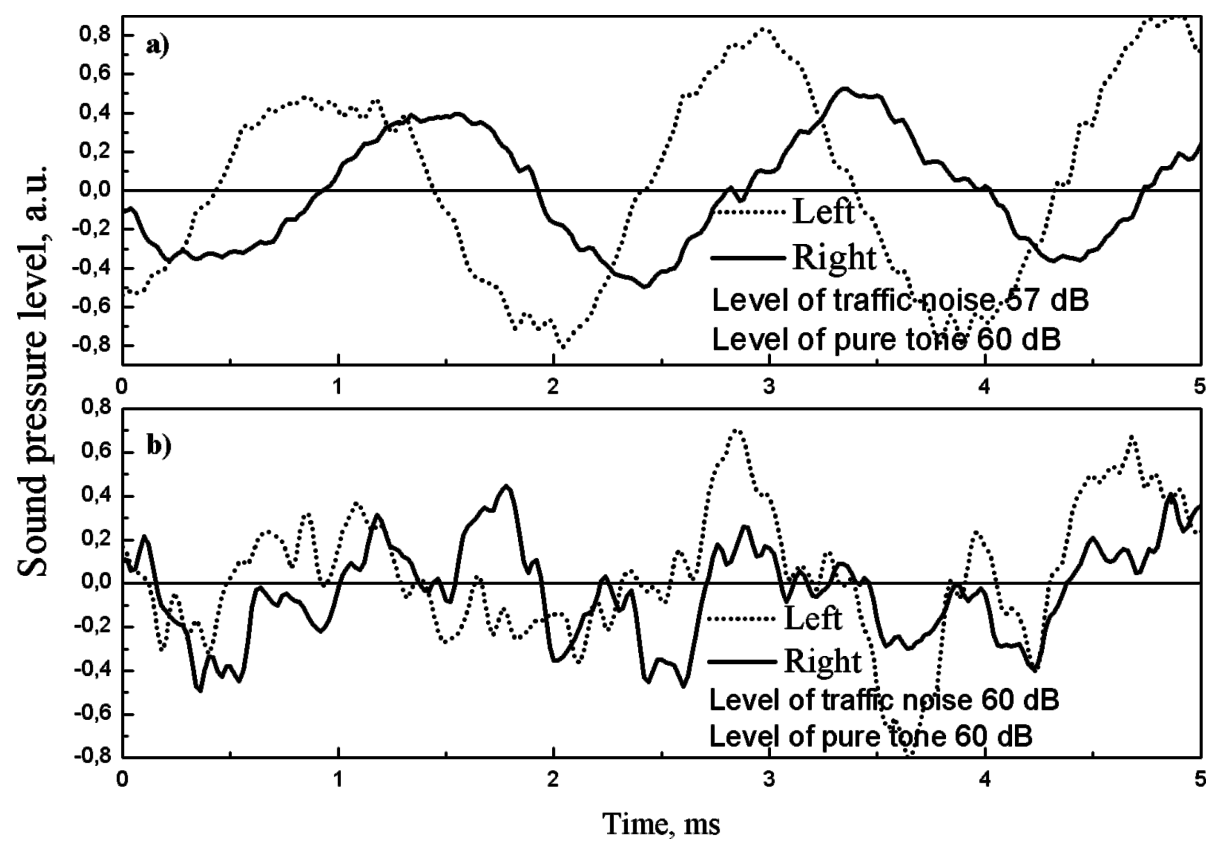

Fig. 8. Interference of pure tone $500 \mathrm{~Hz}$ sound wave with traffic noise: (a) level of traffic noise is $57 \mathrm{~dB}$ ("just perceptible"), (b) level of traffic noise is $60 \mathrm{~dB}$ (equal to pure tone loudness level). Azimuth in both cases is equal to $60^{\circ}$.

rectly with noise analyzer BruelKjaer-2250, the second one was calculated during analysis of sound received by left and right microphones. It can be seen that major part of environmental noises are sounds of lower frequencies. The intensity increase in wind turbine spectrum at higher frequencies (4-5 khz) is caused by the bird chirp which was very intense at the springtime when measurements were taken.

Some peculiarities of human perception of loudness should be admitted. Subjective effects of changes in simple everyday terms, i.e. correspondence to apparent loudness is approximately as follows: $3 \mathrm{~dB}$ is just perceptible, $5 \mathrm{~dB}$ is clearly noticeable, $10 \mathrm{~dB}$ is twice as loud. This means that for a noise measured in decibels on the sound level meter, a difference of $10 \mathrm{~dB}$ represents approximately a doubling or halving of the subjective loudness and a difference of $3 \mathrm{~dB}$ is just noticeable. Therefore, there is no meaning to compare two sounds when difference of their loudness is larger than $10 \mathrm{~dB}$.

Interference of sound wave (pure tone at $500 \mathrm{~Hz}$ ) with traffic noise is presented in Fig. 8. During this measurement one source generated pure tone sound wave and a system of loudspeakers reproduced the traffic noise. The level of pure tone sound was adjusted to $60 \mathrm{~dB}$. Comparison of received sound signals is made for two cases: (a) when the level of traffic noise is $57 \mathrm{~dB}$ ("just perceptible") and (b) when the level of traffic noise is equal to pure tone loudness. Simple calculations allow to evaluate overall loudness: for the first case the sum of both sounds is equal to $61.8 \mathrm{~dB}$
$(57 \mathrm{~dB}+60 \mathrm{~dB})$ and for the second case overall loudness is $63 \mathrm{~dB}(60 \mathrm{~dB}+60 \mathrm{~dB})$. One can see that in the case when the level of traffic noise increases, two signals mix and possibility to use binaural hearing as a cue for spatial localization obviously declines. The threshold loudness of environmental noises which breaks down the ability of binaural hearing is not yet established [9]. Also importance of binaural hearing to the human safety at work places and in the public places is being recognized and more work has to be done in this area.

\section{Conclusions}

It has been shown that the presented experimental system allows one to investigate binaural hearing, which provides the most important cues for the spatial orientation. Comparison of spectra of environmental noises has led to the conclusion that only low frequency range is essential for binaural hearing. The analysis of the cues which are responsible for spatial orientation has revealed that the main mechanism that enables localization of a sound source is interaural time difference. Measurements of the interference between pure tone and environmental noise have shown that noise should increase the threshold loudness for binaural hearing and therefore it may have impact to the human safety and convenience. More work has to be done aiming to establish the threshold for binaural hearing 
in noise environment and measure safe distance, when identification of important sound sources becomes possible.

\section{References}

[1] V. Willert, J. Eggert, J. Adamy, R. Stahl, and E. Korner, A probabilistic model for binaural sound localization, IEEE Trans. Syst. Man Cybern., Part B 36, 982994 (2006).

[2] M. Björkman, Long time measurements of noise from wind turbines, J. Sound Vib. 277, 567-572 (2004).

[3] H. Viste and G. Evangelista, A method for separation of overlapping partials based on similarity of temporal envelopes in multi-channel mixtures, IEEE Trans. Audio Speech Lang. Process. 14, 1051-1061 (2006).
[4] J. Blauert, Spatial Hearing: The Psychophysics of Human Sound Localization, revised ed. (MIT Press, Cambridge, 1997).

[5] W.A. Yost, Hearing thresholds, loudness of sound, and sound adaptation, in: Handbook of Noise and Vibration Control, ed. M.J. Crocker (Wiley, New York, 2007) pp. 286-292.

[6] W.A. Yost, Fundamentals of Hearing: An Introduction, 5th ed. (Academic, San Diego, 2006).

[7] ISO 226:2003 Acoustics, normal equal-loudness-level countours.

[8] G.F. Kuhn, Model for the interaural time differences in the azimuthal plane, J. Acoust. Soc. Am. 62, 157-167 (1977).

[9] M.A. Burges, Environmental noise impact assessment, in: Handbook of Noise and Vibration Control, ed. M.J. Crocker (Wiley, New York, 2007) pp. 1501-1508.

\title{
BINAURINIO GIRDĖJIMO SISTEMOS TAIKYMAS APLINKOS TRIUKŠMO POVEIKIUI VERTINTI
}

\author{
A. Jostaitè, A. Kanapickas \\ Vytauto Didžiojo universitetas, Kaunas, Lietuva
}

\section{Santrauka}

Pateikta eksperimentinè sistema, skirta binaurinio girdèjimo savybėms tirti. Parodyta, kad žemų dažnių srityje nustatant garso šaltinio padèti ypatingai svarbus garso bangos vẻlavimas. Aukštų dažnių srityje pagrindinis indikatorius, padedantis lokalizuoti garso šaltinio padètį, yra garso intensyvumo skirtumas tarp dviejų ausų. Atlikti aplinkos triukšmo spektro tyrimai parodè, kad šiuose spektruose vyrauja žemo dažnio sandai. Tuo būdu rasta, kad aplinkos triukšmas kliudo suvokti garso bangų vẻlavimą, padidindamas binaurinio girdejjimo slenkstį. 